\title{
Analysis of the features of the spatio-temporal distribution of geoelectric inhomogeneities in the Earth's crust and seismic events
}

\author{
Elena Bataleva* \\ Research Station of the RAS in Bishkek, 720049, Kyrgyzstan. Bishkek-49
}

\begin{abstract}
The paper presents the results of experiments carried out at the regime points of magnetotelluric monitoring both on the territory of the Bishkek geodynamic test site (Northern Tien Shan) and on a series of monitoring profiles in various geological conditions. Previous studies indicate the relationship of variations in the electromagnetic and seismic fields, lunisolar tidal effects, seismic regime with the processes of fracturing. The purpose of this work is to establish the features of the relationship between the spatio-temporal distribution of seismicity and the distribution of geoelectric inhomogeneities in the Earth's crust (fault-block tectonics of the region). Based on the analysis of the results of the interpretation of magnetotelluric data (2D inversion) and new detailed seismotomographic constructions, the verification of geoelectric models was carried out, the analysis of the distribution of hypocenters of seismic events was carried out. Special attention was paid to the confinement of earthquakes to listric fault structures. The relationship between the distribution of the hypocenters of seismic events and the spatial position of the electrical conductivity anomalies is confirmed by the authors explanation of the physical nature of the identified conducting structures, based on hypotheses of fluidization and partial melt of the Earth's crust.
\end{abstract}

To date, significant progress has been achieved both in the study of the Central Tien Shan deep structure details (Fig. 1), and in the study of the seismicity distribution therein (Fig. 2) [1-5]. However, the confinement of earthquake sources to geophysical inhomogeneities of the Earth's crust, including fault structures, is still controversial. Based on the existing ideas about the confinement of earthquakes to tectonic faults, it is often impossible to find an explanation for the position of individual seismically active zones in relation to the geological structures observed on the day surface. Based on a comparison of the deep sections of the seismicity distribution field and the geoelectric structure of the zones of dynamic influence of fault structures, the author concluded that there is no compelling reason to connect the distribution of earthquake hypocenters to the near-surface fault zones for the study area. Moreover, on the geoelectric sections given in [1-3], subhorizontal structures are clearly manifested, to which most of the analyzed hypocenters are confined. Apparently, the structure of the stress-strain field is such that it is sensitive to 
sub-horizontal inhomogeneities of the Earth's crust. Taking into account the presence of fluid heterogeneity of the Earth's crust [6] and the fact that the permeability of zones of dynamic influence of faults increases sharply before strong earthquakes [6,7], it is obvious that it is the geoelectric parameters of the geological environment that can serve as indicators of the ongoing geodynamic processes. This paper considers a comparison of the results of the main deep geophysical methods for studying the Earth's crust and the upper mantle - magnetotelluric sounding and seismic tomography, as well as the distribution of seismic events to identify blocks and layers of the Earth's crust with anomalous physical parameters (i.e., determining its stratification and block fault structure), identifying zones of fracturing or decompaction of rocks, which may be associated with fluid-saturated areas.

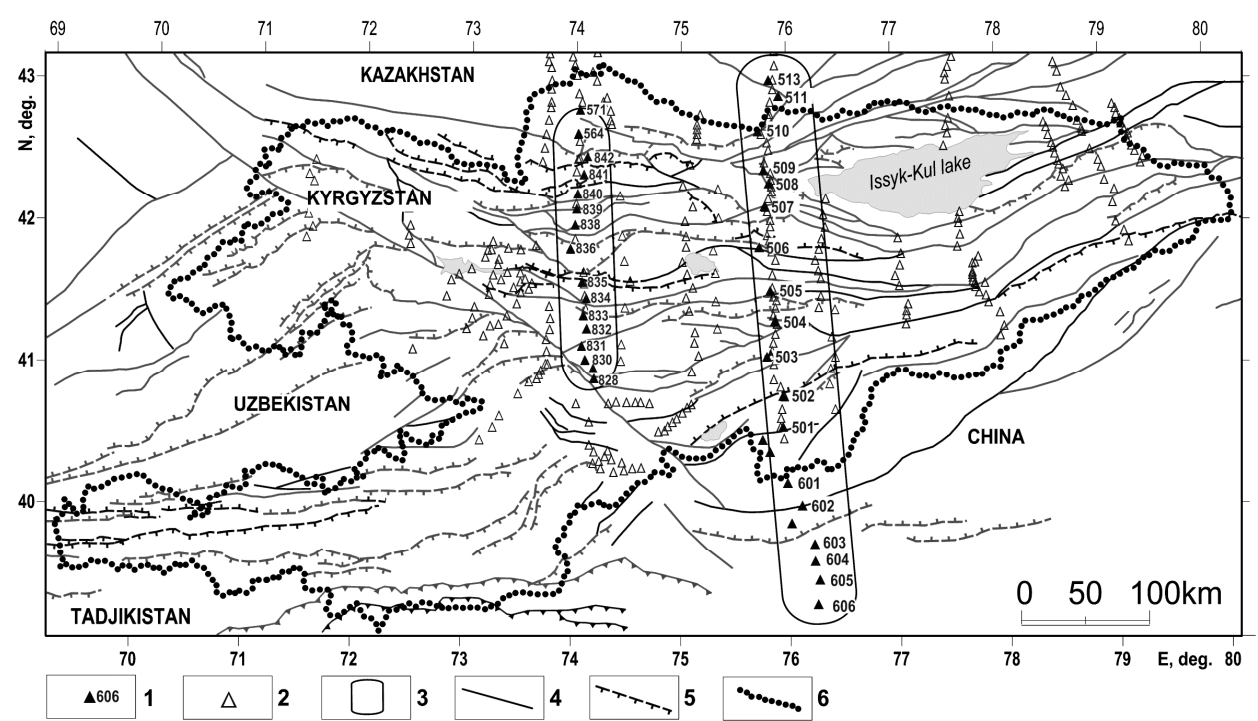

Fig. 1. Scheme of geoelectric exploration of the Central Tien Shan: 1 - points of deep magnetotelluric sounding (DMTS); 2 - points of magnetotelluric sounding (MTS); 3 - MTS profiles considered in the work; 4 - fault structures; 5 - thrusts; 6 - border of the Kyrgyz Republic

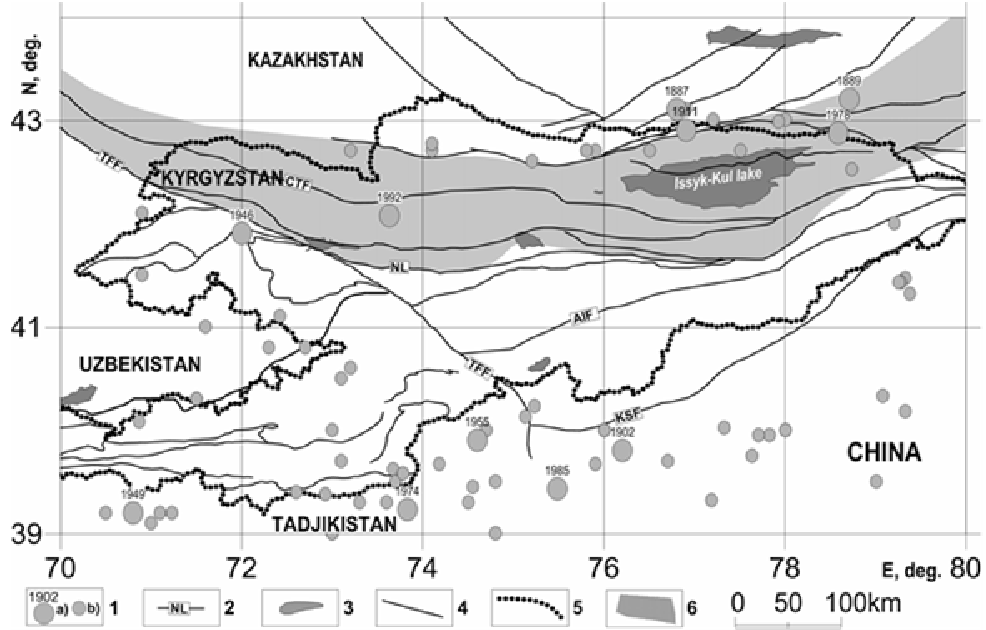

Fig. 2. Distribution of major seismic events in the Central Tien Shan: 1 - a) seismic events with $M>7$, b) seismic events with $\mathrm{M}>6 ; 2$ - largest fault structures: TFF - Talas-Fergana fault, CTF - Central Terskei fault, NL - Nikolaev Line, AIF - Atbashi-Inylchek fault, KSF - Kokshaal fault; 3 - lakes and reservoirs; 4 - tectonic disturbances; 5 - border of the Kyrgyz Republic; 6 - Issyk-Kul microcontinent 
Geoelectric models (Figs. 3,4) are built on the basis of magnetotelluric (MT) sounding data, carried out using a series of detailed and regional profiles by the Phoenix Geophysics stations (Toronto, Canada) [8]. Modern Phoenix MTU-5 equipment is distinguished by high performance, sensitivity and wide dynamic range, reliability, environmental friendliness and ease of use [9]. The recording units of the MTU-5 stations use 24-bit analog-to-digital converters and GPS receivers that provide time synchronization with an accuracy of $1 \mu \mathrm{s}$. The range of the periods of variations of the magnetotelluric field (MTfield) recorded with the MTU-5 is from 0.001 to $1600 \mathrm{~s}$. Measurements of the magnetic field components are performed using standard MTC-50 induction sensors. The electric components of the MT-field are measured in the entire frequency range of registration using L-shaped measuring devices with electric dipoles $50 \mathrm{~m}$ long. The grounding of the dipoles when working with the MTU-5 was carried out using non-polarizable electrodes using manganese-carbon chips, developed and manufactured at the Research Station of the Russian Academy of Sciences. At each sounding point on the territory of the Central Tien Shan, 5 components of the MT-field were recorded in the frequency range $100 \mathrm{~Hz}-1600 \mathrm{~s}$. The magnetotelluric data were processed using robust analysis procedures, in the remote reference (RR) mode. Pseudo-sections $\rho_{\mathrm{k}}$, phases and tippers were inverted using the software package [9].

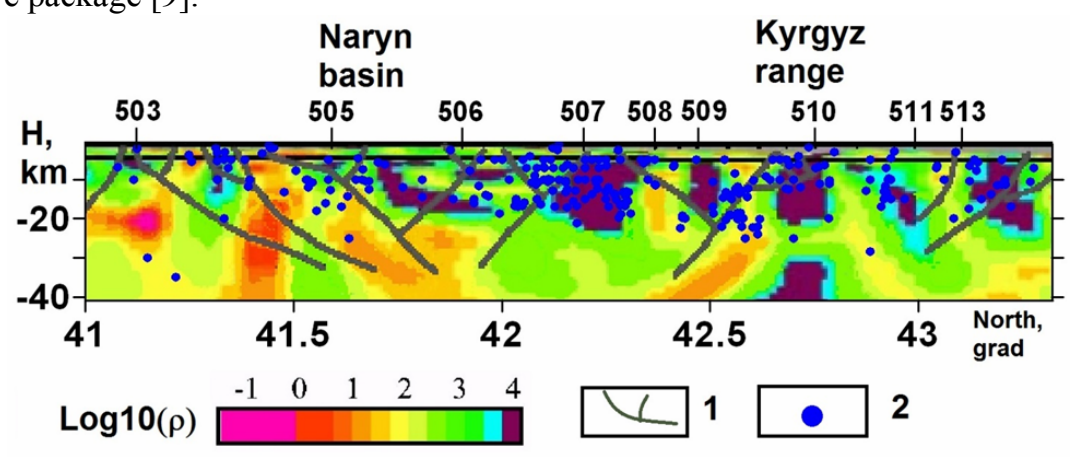

Fig. 3. Distribution of earthquake hypocenters $(M>9)$ in the $+1^{\circ}$ band along the NARYN geophysical profile through the zone of the Issyk-Kul microcontinent. The position of the hypocenters is shown with asterisks, the numbers above the section show the numbers of the points of the DMTS. Fault structures are shown in [16].

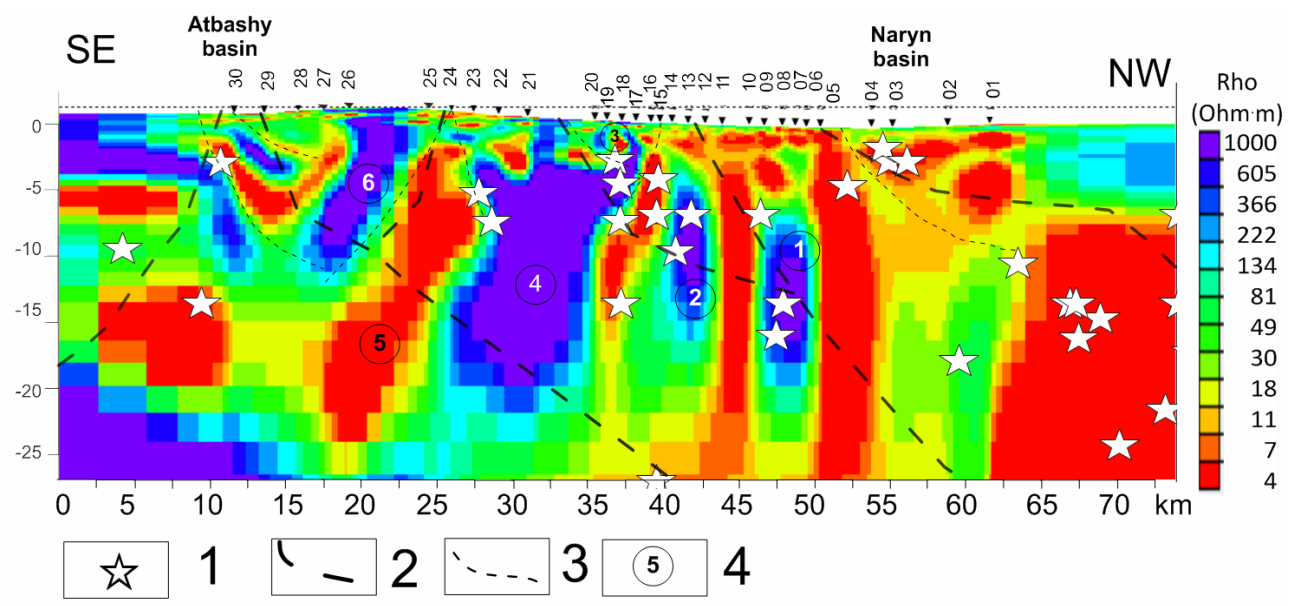

Fig. 4. 2D-inversion model for the "Karabuk" profile $\left(75^{\circ}\right)$, fault structures are shown in the edition [16] 
When calculating the $2 \mathrm{D}$ model for the Naryn profile $\left(76^{\circ}\right)$, the bimodal inversion of the GEOTOOLS system was used, the inverted data ensemble included, in addition to the $\mathrm{TE}$ and TM modes, the components of the Wiese-Parkinson matrix. The final model obtained using parallel inversion is published in [10]. The advantage of this model is its good agreement with modern geological concepts, as well as consistency with seismic data, distribution of depth temperatures, behavior of mantle helium emanations and petrophysical studies [11]. Seismotomographic studies of the Central Tien Shan and adjacent territories were carried out by many authors using different databases and different details [12-15]. In this work, for comparison with the geoelectric model, the most modern and detailed model of the region under study, presented in [15], was selected. An example of the analysis of the comparison of the field distribution of the hypocenters of seismic events, the geoelectric model and the tectonic structure of the Central Tien Shan is shown in Figure 3 [11].

In $[2,3,17]$ studies, the spatial position of earthquake hypocenters in a 100-km strip along the line of the "Naryn" profile was considered. It has been established that all earthquake sources lie in the upper and middle parts of the Earth's crust (at depths less than $30 \mathrm{~km}$ ), while earthquakes in the Tarim area occur at depths of up to $100 \mathrm{~km}$. This can be explained by the existence of various geodynamic settings in the Tien Shan lithosphere, which is reflected in the geodynamic models. The position of earthquakes of energy class $\mathrm{M}>9$, which occurred on the territory of the Central Tien Shan, can be explained by the geoelectric features of the Earth's crust and, first of all, by the presence of high resistance gradients caused by high-resistance bodies and low-resistance zones. The nature of the distribution of geoelectric and seismic (velocity) inhomogeneities is a reflection of geodynamic processes occurring in the Tien Shan lithosphere, for example, seismicity (Figs. 3, 4). The process of collisional interaction continues at the present stage of tectogenesis of the intracontinental orogen. The main indicator of modern activity is seismicity, which is unevenly distributed in different tectonic segments. An analysis of the distribution of earthquake hypocenters may indicate the reactivation of ancient and weakened zones, for example, the Issyk-Kul microcontinent (Fig. 2), in the Earth's crust, which are manifested as pronounced inhomogeneities in geoelectric models [10, 11]. The location of foci of weak earthquakes within high-resistivity objects, which we can observe on the geoelectric model [5], built along the Naryn profile, obviously associated with deep manifestations of magmatism, indicates that stress relief occurs at the contact of blocks of basic rocks with rocks, with other petrophysical and rheological properties.

On the basis of a comprehensive analysis of the distribution of geoelectric and velocity inhomogeneities of the lithosphere of the Central Tien Shan along the Karabuk profile ( $75^{\circ}$ E), it has been established that: a) areas with increased electrical conductivity correspond to areas of lower seismic velocities; b) zones with low electrical conductivity are areas of increased seismic velocities; c) rock massifs identified as a result of complex interpretation of geological and geophysical data as rocks of the Paleozoic basement are characterized by increased seismic velocities. The highest density of hypocenters of seismic events with $\mathrm{M}>9$ is observed at the boundaries of high-resistivity blocks and within them. Noteworthy is the confinement of seismic events to zones of listric faults, which can be traced not only in geoelectric sections, but also in seismotographic constructions (Fig. 5).

Comparison of velocity anomalies in seismotomographic sections and objects of anomalously low electrical resistance in geoelectric sections of the Earth's crust indicates: a) their confinement to fault structures; b) about the listric form of deep faults; c) flattening of faults at depths of $10-20 \mathrm{~km}$ and depths of the top of the crustal conductive layer; d) the existence of zones of increased fracturing or plasticity in the indicated intervals of the Earth's crust; e) on the coincidence of waveguides and zones of increased conductivity.

In the geoelectric structure of the Earth's crust of the Central Tien Shan, a system of multidirectional conducting bodies has been identified, which are identified with fragments 
of deep faults. The structures of low resistivity are spatially confined to the zones of major faults, such as the Nikolaev Line, Atbashi-Inylchek and other fault structures of a lower rank. The conductive zones identified in geoelectric models seem to be mechanically weakened areas of increased fracturing, filled with fluid. For this reason, differences in the values and distribution of the resistances of these conductive zones in the sections under consideration may reflect different levels of fluid concentration or different degrees of connectivity of the pore-fracture space $[18,19]$.
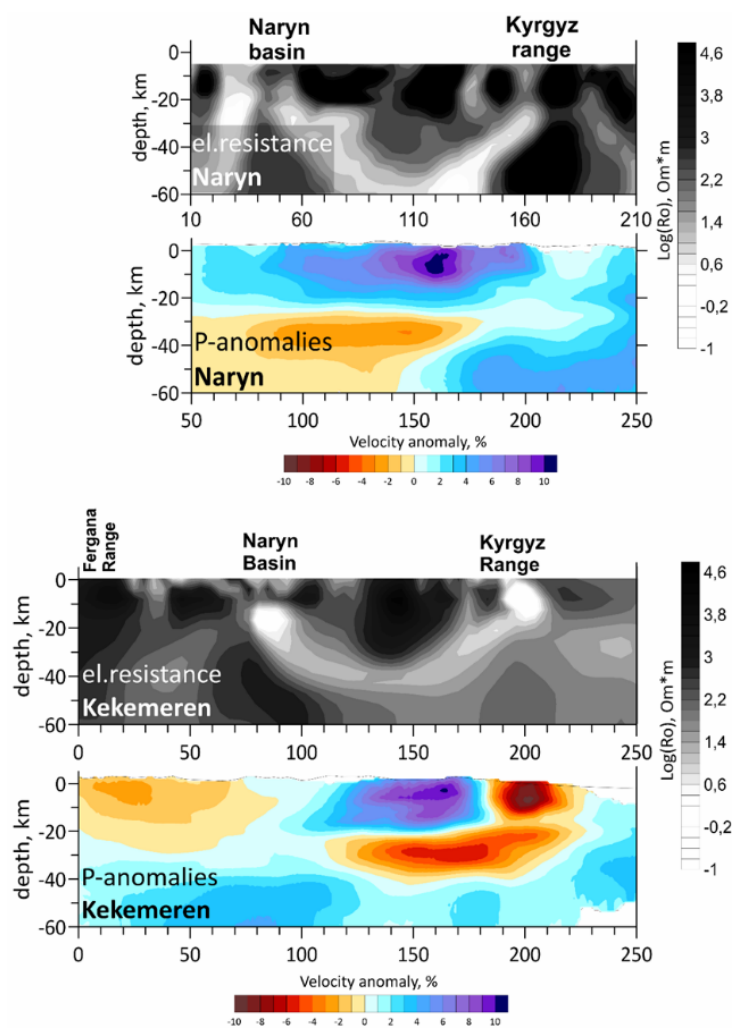

Fig. 5. Comparison of geoelectric models and seismic tomography along the Naryn $\left(76^{\circ} \mathrm{E}\right)$ and Kekemeren $\left(74^{\circ} \mathrm{E}\right)$ profiles (Fig. 1) [15]

The strongest earthquakes of the Tien Shan, taken out on the geoelectric models (Fig. $3,4)$, are confined to the boundaries of blocks and weakened zones, which, as a rule, are also zones of maximum absorption contrast. The structure of the absorption field correlates with the tectonic structure of the area, in particular, the weakened zones correspond to the fault zones [7]. Analysis of the position of the hypocenters of seismic events and the distribution of velocity inhomogeneities in the earth's crust allows us to conclude that earthquakes are confined to high-gradient zones of geoelectric models [2-5]. Very often, these structures flatten out and have the form of listric faults (lateral compression structures) characteristic of areas of intracontinental compression. Flattening, as a rule, occurs at the boundaries of zones with anomalous physical properties - electrical conductivity or velocity characteristics of the medium.

In terms of the depth of occurrence, these seismic events are crustal and, as noted above, the hypocenters of earthquakes in the basement of the Tarim block lie at depths of up to $40 \mathrm{~km}$, while the overwhelming majority of hypocenters of the Tien Shan earthquakes are localized at depths of up to $20 \mathrm{~km}$. The crustal layer with low seismic velocities, 
corresponding to the zone of increased crustal electrical conductivity, practically does not contain earthquake hypocenters, which indicates its fluid saturation and plasticity, i.e. the inability to accumulate elastic energy sufficient for the occurrence of earthquakes.

When comparing the results of the interpretation of magnetotelluric data (2D inversion) and detailed seismotomographic constructions, the verification of geoelectric models was carried out, the nature of crustal electrical conductivity was assessed at various spatial-scale levels. This relationship between the distribution of seismicity and the geoelectric characteristics of the section is confirmed by the authors' explanation of the physical nature of the identified conducting structures, based on hypotheses of fluidization and partial melt of the earth's crust.

The work was carried out within the framework of the state assignment of the Research Station of the Russian Academy of Sciences on the AAAA-A19-119020190063-2 topic.

\section{References}

1. V.D. Bragin, Active Electromagnetic Monitoring of the Bishkek Prognostic Test Area. PhD Thesis (Candidate of Physics and Mathematics). 135 pp, Moscow (2001) (in Russian).

2. Yu.A. Trapeznikov, E.V. Andreeva, V.Yu. Batalev, M.N. Berdichevsky, L.L. Vanyan, A.M. Volykhin, N.S. Golubtsova, A.K. Rybin, Izv. Phys. of Solid Earth. 33, 1-17 (1997).

3. A.V. Zubovich, Y.A. Trapeznikov, V.D. Bragin, O.I. Mosienko, G.G. Schelochkov, A.K. Rybin, V. Y. Batalev, Russ. Geol. Geophys. 42, 1550-1557 (2001).

4. E.A. Bataleva, V.A. Mukhamadeeva, Geodynam. Tectonophys. 9 (2), 461-487 (2018) (In Russian).

5. A.K. Rybin, E.A. Bataleva, K.S. Nepeina, V.E. Matyukov, Geodynamics \& Tectonophysics 12 (3), (2021) (In Russian).

6. I.G. Kissin Dokl. Earth Sci. 448(2), 235-238 (2013).

7. Y.F. Kopnichev, I.N. Sokolova, Seism. Instr. 53, 234-243 (2017).

8. L. Fox, Satellite-Synchronized 3-D Magnetotelluric System. U.S. Patent № 6191587 B1 (2001).

9. W. Rodi, R. Mackie, Geophys. 66, 174-187 (2001).

10. R. A. Bielinski, S. K. Park, A. Rybin, V. Batalev, S. Jun, C. Sears, Geophys. Res. Let., 30, 1806 (2003).

11. V.Yu. Batalev, E.A. Bataleva, V.E. Matyukov, A.K. Rybin, V.V.Egorova, Russ. Geol. Geophys. 52(12), 1592-1599 (2011).

12. A.A. Adamova, T.M. Sabitova, Izv. Phys. of Solid Earth. 40(5), 405-413 (2004).

13. Z.W. Li, S. Roecker, Z.H. Li, B. Wei, H. Wang, G. Schelochkov , V. Bragin, Tectonophys. 477, 49-57 (2009).

14. I.Y. Koulakov, J. Geophys. Res. 116 (B04301), 1-22 (2011).

15. I. Medved, E. Bataleva, M. Buslov, Geosciences, 11, 122 (2021).

16. S.C. Thompson, R.J. Weldon, C.M. Rubin, K. Abdrakhmatov, P. Molnar, G.W. Berger, J. Geophys. Res. 107 (B2203), 1-32 (2002).

17. E.A. Bataleva, V.Y. Batalev, A.K. Rybin Lithosphere. 5, 81-89 (2015).

18. I.G. Kissin, Izv. Phys. of Solid Earth. 32(4), 289-298 (1996).

19. I.G. Kissin, A.I. Ruzaikin, Izv. Phys. of Solid Earth. 33(1), 18-25 (1997). 